\title{
LA EFICACIA DEL PROCESO PENAL ACUSATORIO EN EL PERÚ
}

\section{Christian Salas Beteta*}

\begin{abstract}
"La adopción del sistema acusatorio implica una reforma procesal que va más allá de nuevos plazos y trámites, significa un cambio de concepciones y de instituciones del sistema de administración de justicia y exige de mayores esfuerzos por parte de sus operadores."
\end{abstract}

El autor

Fecha de recibido: 3 de octubre de 2011

Fecha de Aprobación: 7 de diciembre de 2011

Artículo de Reflexión

\begin{abstract}
Resumen
En este artículo se exponen los aciertos y los vacíos que ha traído la implementación de la modalidad de justicia en el Perú, bajo la técnica de la Oralidad; Normatividad que inicia su vigencia a partir del año 2006 y que, en la actualidad, apenas comienza a reflejar resultados prácticos y debates en los escenarios académicos. Si bien el nuevo esquema ha contribuido a la descongestión de los despachos judiciales y a la debida protección de las víctimas, no obstante el asunto presupuestal ha obstaculizado la toma de decisiones y el oportuno proferimiento de sentencias; al igual que se identifican contradicciones de interpretación y dificultades prácticas en su aplicación, que serán materia de la presente disertación.
\end{abstract}

\section{Palabras clave}

Administración de justicia, Proceso penal, oralidad, garantismo, sujetos procesales.

\section{THE EFFECTIVENESS OF ADVERSARIAL CRIMINAL PROCESS IN PERU}

\begin{abstract}
In this article the successes and the defects are exposed such as has brought the implementation of the modality of justice in the Peru, under the technique of the Orality; legacy that begins their validity since the year 2006 and that, at the present time, it hardly begins to reflect practical results and debates in the academic scenarios. Although, the new scheme of composition has contributed to the decongest the judicial offices and the due protection of the victims, nevertheless the matter budget has blocked the taking of decisions and
\end{abstract}

* Presidente de la Escuela de Litigación Oral y Técnicas de Negociación de Perú. Conferencista internacional sobre la reforma procesal penal en Latinoamérica. Profesor de Derecho Procesal Penal en la Facultad de Derecho de la Universidad Privada San Juan Bautista. Miembro de la Comisión Consultiva de Derecho Procesal Penal y Cortes Internacionales del Colegio de Abogados de Lima. Maestría en Derecho Procesal por la Universidad San Martín de Porres. Especializado en destrezas de litigación oral por USAID-OEA y ONUDC. Autor de los libros: "Curso de lógica jurídica: razonamiento y argumentación jurídica» (2008), «Trascendencia de las técnicas de litigación oral en el proceso penal» (2010) y «El proceso penal común» (2011). Actualmente es consultor de la Procuraduría Pública Especializada en Delitos de Corrupción. www.salasbeteta.com 
the opportune judgments; the same time as interpretation contradictions and practical difficulties are identified in their application that will be matter of the present dissertation.

\title{
Keywords
}

Administration of justice, penal Process, orality, guarantee, procedural fellows.

\section{A EFICÁCIA DA CONTRADITÓRIOCRIMINAL NO PERU}

\begin{abstract}
Resumo
Neste artigo os sucessos e os defeitos estão expostos como trouxe a implementação da modalidade de justiça no Peru, debaixo da técnica da Oralidade; legado que começa a validez deles/delas desde o ano 2006 e que, na atualidade, apenas começa a refletir resultados práticos e debates nos enredos acadêmicos. Embora, o esquema novo de composição contribuiu o descongestione os escritórios judiciais e a proteção devida das vítimas, não obstante o orçamento de assunto bloqueou a tomada de decisões e os julgamentos oportunos; o mesmo tempo como contradições de interpretação e dificuldades práticas é identificado na aplicação deles/delas que será questão da dissertação presente.
\end{abstract}

\section{Palavras chave}

Administração de justiça, Processo penal, oralidade, garantia, companheiros processuais.

\section{INTRODUCCIÓN}

El Perú ha sido uno de los últimos países de Latinoamérica en sumarse a la ola reformista de los sistemas de justicia penal, rumbo a un sistema acusatorio. La reforma procesal penal peruana puesta en marcha en el año 2006, con la implementación progresiva del Código Procesal Penal del 2004 (en adelante CPP-2004), ha alcanzado, de un lado, niveles de eficacia procesal relacionados con la descarga de los despachos judiciales, la celeridad en la tramitación del procedimiento y la pronta reparación integral para las víctimas de los delitos y de otro lado, ha evidenciado vacíos y deficiencias de algunas de sus disposiciones, contradicciones de interpretación, así como dificultades prácticas en su aplicación, que serán materia del presente comentario.

Como es obvio, resulta de utilidad puntualizar aquellos aspectos que dificultan los objetivos de la reforma, a fin de asentar los cimientos del sistema acusatorio y corregir los defectos que sólo la experiencia puede demostrar. Sin duda, toda reforma procesal tiene implicaciones jurídicas, pero también sociales, políticas, culturales y económicas; tanto así, que la mayoría de expertos coinciden en afirmar que no basta con la modificación o dación de leyes sustantivas o adjetivas, para lograr una real reforma del sistema de administración de justicia penal, sino de un alto grado de inversión por parte del Estado, estabilidad económica, mayor compromiso de la sociedad civil y un cambio de mentalidad.

La tan esperada y urgente reforma procesal penal en el Perú, ha tenido también gran repercusión en el mundo académico, donde -positivamente-se ha intensificado el debate y los estudios al respecto en todos los niveles. Este comentario es muestra de ello y esperamos que sirva para ilustrar al lector acerca del estado actual de la reforma en el Perú y para esclarecer algunas dudas o, mejor aún, para avivar el debate, finalidad inherente a todo trabajo académico. 


\section{LA REFORMA PROCESAL PENAL EN LATINOAMÉRICA}

El proceso de reforma de la justicia criminal en Latinoamérica data de hace aproximadamente dos décadas. Conforme señalan los tratadistas DUCE, FUENTES y RIEGO, «[l]as razones que motivaron este proceso de reforma son de distinta índole, encontrándose dentro de ellas, y de manera muy general, los abusos a los derechos fundamentales en el contexto del proceso penal inquisitivo y la poca eficiencia de este en la persecución penal. Este proceso de reforma alcanzó a la mayoría de los países del continente y se ha orientado en general en la misma dirección: reemplazar los diversos tipos de sistemas inquisitivos vigentes por modelos procesales de carácter acusatorio.» (Duce, Fuentes y Riego, 2009, p. 20).

En la década de los noventa, países como Guatemala $^{1}$, Argentina $^{2}$, Costa Rica $^{3}$, El Salvador 4 y Venezuela ${ }^{5}$, iniciaron los procesos de reforma procesal penal hacia al sistema acusatorio. A partir del año 2000, Bolivia ${ }^{6}$, Paraguay ${ }^{7}$, Chile ${ }^{8}$, Ecuador $^{9}$, Honduras ${ }^{10}$, Nicaragua ${ }^{11}$, República

1 Guatemala: Decreto № 51-92, Código Procesal Penal vigente desde 1994.

2 Argentina: Ley $N^{\circ} 11922$, Código Procesal Penal de la Provincia de Buenos Aires vigente desde 1998.

3 Costa Rica: Ley N ${ }^{\circ}$ 7594, Código Procesal Penal vigente desde 1998.

4 El Salvador: Decreto Legislativo $N^{\circ}$ 904, Código Procesal Penal vigente desde 1998.

5 Venezuela: Gaceta Oficial No 5.558 (Extraordinaria), Código Orgánico Procesal Penal vigente desde 1999.

6 Bolivia: Ley N 1970, Código de Procedimiento Penal vigente desde 2000 .

7 Paraguay: Ley $N^{\circ} 1286 / 98$, Código Procesal Penal vigente desde 2000.

8 Chile: Ley $\mathrm{N}^{\circ}$ 19.696, Código Procesal Penal vigente desde 2000.

9 Ecuador: Ley $\mathrm{N}^{\circ}$ 000. RO/ Sup 360, Código de Procedimiento Penal vigente desde el 2001.

10 Honduras: Decreto N ${ }^{\circ}$ 9-99-E, Código Procesal Penal vigente desde 2002.

11 Nicaragua: Ley N 406, Código Procesal Penal vigente desde 2002.
Dominada $^{12}$, Colombia ${ }^{13}$, Perú ${ }^{14}$, México ${ }^{15}$, Panamá $^{16}$ y Uruguay $^{17}$ se sumaron a la ola reformista e iniciaron el proceso de reforma procesal penal, implementando-en algunos casos de manera total y en otros de forma gradual o progresiva- códigos adjetivos basados en los principios del sistema acusatorio, evidenciando a la fecha diversos resultados.

\section{EVOLUCIÓN LEGISLATIVA DEL PROCESO PENAL PERUANO}

En el año 1940 entró en vigencia la Ley $\mathrm{N}^{\circ}$ 9024, Código de Procedimientos Penales ${ }^{18}$, que estableció el llamado "proceso ordinario». Este proceso consistía en dos etapas: la instrucción, fase de investigación realizada por el juez, y el juzgamiento, fase en la cual, el órgano jurisdiccional superior realiza el juicio oral y emitía sentencia. Como podemos apreciar, el proceso ordinario tenía una mixtura de dos sistemas (inquisitivo y acusatorio), pero la conformación de este proceso, aunado a la insuficiencia e incapacidad de los operadores de justicia, el incremento de la población y demás factores ${ }^{19}$ propiciaron una sobrecarga de los despachos judiciales, que tornó en inmanejable el aparato judicial.

12 República Dominicana: Ley N 76-02, Código Procesal Penal vigente desde 2004.

13 Colombia: Ley $\mathrm{N}^{\circ}$ 906, Código de Procedimiento Penal vigente desde 2005.

14 Perú: Decreto Legislativo N N 957, Código Procesal Penal vigente desde 2006.

15 México: Decreto DOF 18/06/2008, reforma constitucional vigente a partir de 2008.

16 Panamá: Ley $\mathrm{N}^{\circ}$ 63, Código Procesal Penal vigente desde 2009.

17 Uruguay: Ley 9.754, Código Procesal Penal vigente desde 2009.

18 Ley $\mathrm{N}^{\circ} 9024$ - Código de Procedimientos Penales, promulgado el 23 de noviembre de 1939.

19 Entre otros factores destacan la lentitud de la tramitación del proceso ordinario, las maniobras dilatorias empleadas por los litigantes y los índices de corrupción a nivel judicial. 
En 1968, se modificó el Código de Procedimientos Penales $^{20}$, a través del Decreto Ley $\mathrm{N}^{\circ} 17110$, estableciéndose normas procesales tendientes a conseguir «una pronta y oportuna administración de la justicia penal», mediante la implantación de un "proceso sumario», otorgándose la facultad de fallo a los jueces instructores en determinados delitos. Este proceso consistía en una sola fase, la instrucción, en la que un juez investigaba y dictaba la sentencia al culminar. No existía fase de juzgamiento, lo que a todas luces atentaba contra derechos fundamentales de los ciudadanos, siendo por ende inconstitucional.

Conforme señala NEYRA FLORES, (2007) «con la dación de este decreto ley, se abre paso a un régimen de excepción, que iría restringiendo progresivamente la realización del juicio oral en determinados delitos hastallegar a una sumarización de los procedimientos en la totalidad de delitos, lo que inicialmente se constituyó como una excepción, posteriormente lo encontraríamos como una regla» (p. 20).

En 1981, a través del Decreto Legislativo $\mathrm{N}^{\circ} 124$, Ley del proceso penal sumario ${ }^{21}$, se amplió el número de figuras susceptibles de juzgamiento en la vía sumaria y se adecuó el procedimiento a las atribuciones de los fiscales señalas en la Ley Orgánica del Ministerio Público 22 (la facultad de intervenir en la investigación policial, de ofrecer pruebas de cargo y de vigilar el proceso penal).

Un primer intento de reforma procesal penal se dio en 1991, con la promulgación del Código Procesal Penal ${ }^{23}$, basado en el sistema acusatorio garantista, pero que nunca llegó a entrar

20 Mediante Decreto Ley $N^{\circ} 17110$, de fecha 3 de Octubre de 1968, se modificó el Código de Procedimientos Penales.

21 Decreto Legislativo $N^{\circ} 124$ - Ley del proceso penal sumario, de fecha 12 de junio de 1981.

22 Decreto Legislativo $\mathrm{N}^{\circ} 052$, Ley Orgánica del Ministerio Público, de fecha 18 de marzo de 1981.

Decreto Legislativo № 638 - Código Procesal Penal, promulgado el 25 de abril de 1991 y publicado el 27 de abril de 1991. Sólo entraron en vigencia los artículos 2, 135, 136, 137, 138, 143, 144, 145, 182, 183, 184, $185,186,187,188,239,240,241,142,143,144$ y 145. Derogado por el Decreto Legislativo № 957. completamente en vigencia, debido a la ruptura del régimen democrático en 1992 y a la falta de decisión política por parte de los sucesivos gobiernos, constituyendo uno de los grandes fracasos de la reforma procesal penal en el Perú ${ }^{24}$.

De ese modo, a inicios del Siglo XXI, la justicia penal en el Perú se volvió insostenible. La mayoría de delitos del Código Penal se tramitaban judicialmente bajo el inefable proceso sumario. Sobrecarga procesal, carencia de infraestructura y recursos humanos, deficiencias en capacitación y calidad de los operadores de justicia, altos índices de corrupción, reclamos sociales, entre otros hechos hicieron necesario un cambio.

\section{EL CÓDIGO PROCESAL PENAL DE 2004 Y SU IMPLEMENTACIÓN}

En el año 2004 se promulgó el Decreto Legislativo $N^{\circ}$ 957, Código Procesal Penal ${ }^{25}$ por el cual el Perú adecuó el proceso penal al sistema acusatorio. Este cuerpo legal empezó a aplicarse dos años después de su promulgación, de manera gradual ${ }^{26}$, es decir, que el código adjetivo

23 Decreto Legislativo N ${ }^{\circ} 638$ - Código Procesal Penal, promulgado el 25 de abril de 1991 y publicado el 27 de abril de 1991. Sólo entraron en vigencia los artículos 2, 135, 136, 137, 138, 143, 144, 145, 182, 183, 184, $185,186,187,188,239,240,241,142,143,144$ y 145. Derogado por el Decreto Legislativo $N^{\circ} 957$.

24 «El siguiente paso para la sumarización del proceso penal se da en 1996, fecha en que se publica la Ley N ${ }^{\circ} 26689$, que enumera de manera taxativa los procesos sujetos a la tramitación ordinaria, convirtiendo la excepción (procedimiento sumario) en regla. En el año 2001, esta lista se precisa aún más y lo que finalmente queda del panorama del proceso es una estructura en la cual el $90 \%$ de delitos se tramitan mediante el procedimiento sumario, quedando sólo el 10\% de los delitos sujetos al trámite ordinario». NEYRA FLORES, José. op. cit. P. 20.

25 Decreto Legislativo N 957 - Código Procesal Penal, promulgado el 22 de julio de 2004 y publicado el 29 de julio de 2004.

26 Cronograma de implementación del Código Procesal Penal de 2004. Véase: Decreto Supremo 013-2005JUS, Decreto Supremo 007-2006-JUS, Decreto Supremo 005-2007-JUS, Decreto Supremo 016-2009JUS, Decreto Supremo 016-2010-JUS, Ley No 29574 , Ley N ${ }^{\circ} 29648$ y Decreto Supremo 004-2011-JUS. 
se viene implementando por fechas determinadas en diversos distritos judiciales del país.

Actualmente, el Perú cuenta con 30 distritos judiciales, que son los ámbitos de competencia que delimitan la jurisdicción. El CPP-2004 se puso en vigencia en el 2006, a modo de plan piloto en el distrito judicial de Huaura ${ }^{27}$; en el 2007, en La Libertad; en el 2008, en Tacna, Moquegua y Arequipa; en el 2009, en Tumbes, Piura, Lambayeque, Puno, Cusco, Madre de Dios, Ica y Cañete; y en el 2010, en Cajamarca, Amazonas, San Martín, Ancash y Santa. Durante el año 2011 se suspendió la implementación por razones presupuestales, disponiéndose que en el año 2012 se aplique en Ancash, Santa, Pasco, Huánuco, Ucayali y Loreto; culminándose en el 2013 con los distritos judiciales de Apurímac, Huancavelica, Ayacucho, Junín, Callao, Lima Norte, Lima Sur y lima.

Una de las decisiones políticas más cuestionadas fue la aplicación del CPP-2004 sólo para casos referidos a los delitos contra la administración pública (corrupción de funcionarios, peculado, etc.) a partir de enero de 2011 en Lima y demás distritos judiciales que aún no contaban con el nuevo código, sin que previamente se hubiera capacitado a los operadores jurídicos, ni se adecuaran los ambientes institucionales. El caso es que a la fecha, el CPP-2004 se aplica a nivel nacional para dicho tipo de delitos.

En suma, en el Perú se viene realizando una reforma procesal-sea porque las tendencias doctrinarias y legislativas de la región la impulsaron, sea porque el caótico sistema de administración de justicia lo hicieron urgentemente necesario-implicando un cambio del sistema mixto a uno acusatorio, caracterizado por diseñar un proceso penal basado en el respeto de los derechos humanos,

27 El distrito judicial de Huaura se encuentra ubicado al norte de la región Lima, tiene una extensión territorial de 13,305 km2 y comprende las provincias de Huaura, Barranca, Huaral, Oyón y Cajatambo. Información disponible en línea al mes de octubre de 2011 en: www.mpfn.gob.pe/distrito_judicial/informacion. php?dj= huaura contenidos en instrumentos internacionales y en la Constitución Política.

\section{PRINCIPALES CARACTERÍSTICAS DEL NUEVO PROCESO PENAL PERUANO}

\subsection{La visión constitucional del proceso penal}

El proceso penal importa un conjunto de principios y garantías constitucionales que guían y gobiernan su desenvolvimiento, así como el rol de los sujetos procesales. En un proceso basado en el sistema acusatorio, la dignidad humana como pilar del Estado democrático de Derecho, es un derecho fundamental cuyo respeto se exige al máximo durante el desarrollo del proceso penal. La libertad es otro derecho fundamental, que constituye una regla general en el nuevo proceso y que puede ser restringida sólo bajo los supuestos legalmente establecidos, de modo que, la detención pasa a ser la medida excepcional en el proceso. El derecho de defensa, como derecho irrestricto, no se activa a partir de la acusación fiscal, sino desde el mismo momento en que la persona tiene conocimiento que se ha iniciado una indagación o investigación preliminar en su contra. La presunción de inocencia, la igualdad procesal, la tutela jurisdiccional efectiva, la cosa juzgada, entre otros, son los principios y garantías que gobiernan al debido proceso penal.

El fin del proceso penal no sólo consiste en la imposición de la pena al autor o partícipe de un hecho punible, sino también en la búsqueda de la mejor manera de solucionar el conflicto derivado del delito. De modo que, la legalidad y la racionalidad, dan origen a la oportunidad como posibilidad de orientar todo comportamiento humano, especialmente de las personas que ejercen autoridad, aplicando medidas alternativas al procedimiento y a la pena. Así, los mecanismos de simplificación procesal -tales como el principio de oportunidad, los acuerdos reparatorios, la terminación anticipada, la colaboración eficaz, la conclusión anticipada 
del juicio- constituyen otra característica del nuevo proceso penal.

\subsection{El garantismo y la eficacia}

El CPP-2004 se inspira en el mandato constitucional de respeto y garantía de los derechos fundamentales de la persona, en aras de evitar que el ius puniendi que ejerce el Estado, afecte ilegal e injustificadamente derechos fundamentales de la persona sometida a una investigación o proceso penal. No obstante, debemos entender la aspiración real de establecer un balance razonable entre el garantismo y las atribuciones de persecución, coerción y sanción penal del Estado, a través de sus órganos competentes. Hemos de buscar ese equilibro eficaz para la administración de justicia penal, en tanto el garantismo radical e irracional abre las puertas a la impunidad y a la peligrosa desacreditación del sistema de justicia ante la sociedad.

La visión garantista del proceso se fundamenta en el principio de limitación del poder, que informa a todo Estado democrático de derecho, donde el poder de sus autoridades está limitado, entre otros factores, por los derechos fundamentales de la persona, reconocidos en la Constitución y en los instrumentos internacionales de derechos humanos, que se incorporan al derecho interno. Por ello, el Título Preliminar del CPP-2004 recoge los principios de gratuidad de la administración de justicia penal, garantía del juicio previo, la doble instancia, igualdad procesal, presunción de inocencia, interdicción de la persecución penal múltiple, inviolabilidad de la defensa, legitimidad de la prueba, legalidad de las medidas limitativas de derechos, entre otros. Y en el artículo X del Título Preliminar ${ }^{28}$, los considera prevalentes en relación al resto de disposiciones de dicho código, constituyendo una fuente y fundamento para su interpretación. Ello quiere decir que los contenidos interpretativos que desarrollen los operadores judiciales, tendrán que ser compatibles con el conjunto de valores, principios y normas de rango constitucional.

28 Artículo X.- Prevalencia de las normas de este Título: "Las normas que integran el presente Título prevalecen sobre cualquier otra disposición de este Código. Serán utilizadas como fundamento de interpretación".
Asimismo, debe tenerse en cuenta que las víctimas del hecho punible, no sólo tienen derecho a una reparación económica, sino a una reparación integral. Ello implica que no pueden desconocerse sus derechos en el proceso penal. La víctima tiene derecho a la verdad, a la justicia y a la reparación, para ello la ley le debe garantizar $-\mathrm{y}$ las autoridades materializar- los derechos a la información, protección física y jurídica, petición, intervención y reparación integral.

\subsection{El nuevo procedimiento penal: el denominado "proceso común»}

El CPP-2004 establece un trámite común ${ }^{29}$ para todos los delitos contenidos en el Código Penal, dejando atrás el procedimiento ordinario (mixto) y el inconstitucional procedimiento sumario (inquisitivo), caracterizado por ser eminentemente escrito, reservado y sin juicio oral. Dicho "proceso común» cuenta con tres etapas ${ }^{30}: 1$ ) la investigación preparatoria, 2) la etapa intermedia y 3) la etapa de juzgamiento o juicio oral.

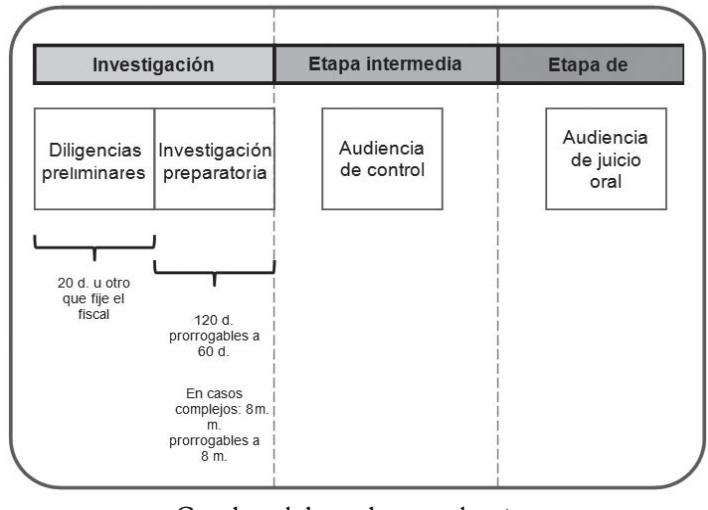

Cuadro elaborado por el autor.

29 El CPP-2004 regula los siguientes procesos especiales: el proceso inmediato, el proceso por delitos de función, el proceso de seguridad, el proceso por delito de ejercicio privado de la acción penal, el proceso de terminación anticipada, el proceso por colaboración eficaz y el proceso por faltas.

30 Según SÁNCHEZ VELARDE, el proceso común cuenta con cinco etapas: 1) investigación preliminar; 2) investigación preparatoria; 3) Etapa intermedia; 4) Etapa de Juzgamiento y 5) Etapa de ejecución. SÁNCHEZ VELARDE, Pablo. Introducción al Nuevo Proceso Penal. Editorial Moreno SA, Lima, 2005. 
La investigación preparatoria, es la primera etapa del proceso común y tiene dos sub-fases: las diligencias preliminares y la investigación preparatoria formalizada. Las primeras tienen un plazo de 20 días u otro que fije el fiscal, ateniendo a las características, complejidad y circunstancias de los hechos objeto de investigación y tienen por finalidad, determinar el carácter delictuoso del hecho investigado e individualizar a los presuntos autores y a los agraviados. Por su parte, la investigación preparatoria formalizada, tiene un plazo de 120 días prorrogables a 60 días y en los casos complejos, puede durar hasta 8 meses prorrogables por igual plazo y su finalidad es reunir los elementos de convicción, a fin de sustentar la decisión fiscal. En el antiguo proceso penal peruano la investigación no tenía plazos.

La investigación preparatoria es dirigida por el fiscal y consiste en la recolección de informaciones, datos, evidencias, indicios y demás elementos (tanto de cargo como de descargo) que le sirvan para sustentar su decisión (sea acusación o sobreseimiento). Dicha labor la realiza con el apoyo de la policía, la cual está obligada a ello por mandato constitucional. La Policía Nacional como órgano técnico auxiliar, debe realizar -bajo la dirección del fiscal- una investigación objetiva, es decir, destinada a la ubicación, identificación, fijación, análisis y procesamiento de las evidencias y testimonios, a través de métodos objetivos, sean técnicos o científicos, aplicando los procedimientos que aseguren la autenticidad del objeto y la veracidad de los hechos, dejando de lado todo elemento subjetivo o prejuicioso. En el antiguo proceso penal la investigación había caído - de facto- en manos de la policía, presentándose serias irregularidades.

La etapa intermedia, comienza con la disposición de conclusión de la investigación preparatoria. En esta etapa el juez de la investigación preparatoria (que debiera denominarse juez de garantías) interviene para controlar el pedido (acusación o sobreseimiento) del fiscal. Esta etapa sirve de filtro para sanear los cuestionamientos u observaciones a aspectos formales de la acusación, así como para resolver los medios de defensa técnicos planteados, admitir o rechazar los medios probatorios ofrecidos por las partes, entre otros. Si se acepta el requerimiento de sobreseimiento del fiscal, el procedimiento concluye, una vez que el auto de sobreseimiento quede firme. Si el juez de la investigación preparatoria considera que hay mérito para juicio oral, emite un auto de enjuiciamiento y remite los actuados al juez penal.

El juzgamiento, se desarrolla bajo el debate entre el acusador y el defensor. En esta etapa se actúan las pruebas y el órgano jurisdiccional las valora, a efectos de emitir su decisión. Existen reglas para la admisión y valoración de la prueba, de modo que, aquélla que fuere obtenida con vulneración del contenido esencial de los derechos fundamentales, resulta inadmisible y el juzgador sólo valorará las pruebas incorporadas legítimamente en el juicio oral. Como hemos explicado, la investigación preparatoria tiene por finalidad recabar los elementos de convicción suficientes, para sustentar la acusación fiscal en la etapa intermedia; en tanto que, el juzgamiento es la fase del proceso en la que el juzgador se pronunciará sobre el fondo, decidiendo sobre la responsabilidad penal del procesado y para ello se requiere de una debida actividad probatoria. Por tanto, la prueba se producirá en el juicio oral bajo los principios de oralidad, publicidad, inmediación y contradicción, correspondiendo a las partes, a través de sus argumentos, exponer sus resultados y hacerlas ingresar al ámbito psicológico del juzgador, dirigiendo su actividad a generarle convicción.

La decisión judicial que se pronuncia acerca de la responsabilidad o inocencia del acusado puede ser impugnada y será resuelta por la Sala de Apelaciones, atendiendo al debate que efectúen las partes en la audiencia respectiva. A diferencia del antiguo Código de Procedimientos Penales ${ }^{31}$, el CPP-2004 regula ordenadamente los recursos impugnatorios.

31 Ley $\mathrm{N}^{\circ} 9024$ - Código de Procedimientos Penales, publicada el 23 de noviembre de 1939. 


\subsection{Roles de los sujetos procesales}

El sistema acusatorio se caracteriza esencialmente por la clara división de funciones, que los sujetos procesales deben cumplir en el proceso penal. La separación de funciones implica que las dos fases fundamentales de la persecución penal que tiene a cargo el Estado, sean desarrolladas por órganos diferentes. Así, el nuevo marco procesal encarga la imputación penal al Ministerio Público ${ }^{32}$, órgano constitucional autónomo, y el juzgamiento, al Poder Judicial ${ }^{33}$, órgano jurisdiccional. Esta división garantiza que el juzgador -al momento de desarrollar el juicio y emitir sentencia- no se vea afectado por el prejuicio que genera la labor de investigación. Todo investigador busca hallar elementos de convicción, que acrediten la responsabilidad del investigado en la comisión de los hechos. En cambio, un decidor-como lo es el juez-debe ser imparcial.

Los roles de los sujetos procesales dependen de la fase o etapa procesal en la que se encuentran. En el siguiente cuadro podemos apreciar los roles del fiscal, defensor y juez en las etapas del proceso común.

\begin{tabular}{|c|c|c|c|}
\hline Sujeto procesal & Investigación preparatoria & Etapa Intermedia & Etapa de juzgamiento \\
\hline FISCAL & $\begin{array}{l}\text { - Titular del ejercicio de la } \\
\text { acción penal pública. } \\
\text { - Tiene el deber de la carga de } \\
\text { la prueba. } \\
\text { - Director jurídico de la inves- } \\
\text { tigación. La conduce desde } \\
\text { el inicio. } \\
\text { - Obligado a actuar con } \\
\text { objetividad, indagando los } \\
\text { hechos constitutivos de delito, } \\
\text { los que determinen yacrediten } \\
\text { la responsabilidad o inocencia } \\
\text { del imputado. } \\
\text { - Conduce y controla jurídica- } \\
\text { mente los actos de investiga- } \\
\text { ción que realiza la policía. }\end{array}$ & $\begin{array}{l}\text { Culminada la investigación } \\
\text { preparatoria tiene dos opciones: } \\
\text { a) Solicita el sobreseimiento } \\
\text { b) Formula acusación. } \\
\text { Sustentará su pedido ante el juez } \\
\text { de investigación preparatoria. }\end{array}$ & $\begin{array}{l}\text { - Es parte acusadora. } \\
\text { - Interviene exponiendo sus } \\
\text { argumentos de acusación } \\
\text { (teoría del caso) y actúa } \\
\text { sus medios probatorios } \\
\text { admitidos. }\end{array}$ \\
\hline
\end{tabular}

32 Artículo IV del Título Preliminar del CPP-2004: Titular de la acción penal.-

1. El Ministerio Público es titular del ejercicio público de la acción penal en los delitos y tiene el deber de la carga de la prueba. Asume la conducción de la investigación desde su inicio.

2. El Ministerio Público está obligado a actuar con objetividad, indagando los hechos constitutivos de delito, los que determinen y acrediten la responsabilidad o inocencia del imputado. Con esta finalidad conduce y controla jurídicamente los actos de investigación que realiza la Policía Nacional.

3. Los actos de investigación que practica el Ministerio Público o la Policía Nacional no tienen carácter jurisdiccional. Cuando fuera indispensable una decisión de esta naturaleza la requerirá del órgano jurisdiccional, motivando debidamente su petición.

33 Artículo V del Título Preliminar del CPP-2004: Competencia judicial.-

1. Corresponde al órgano jurisdiccional la dirección de la etapa intermedia $y$, especialmente, del juzgamiento, así como expedir las sentencias y demás resoluciones previstas en la Ley.

2. Nadie puede ser sometido a pena o medida de seguridad sino por resolución del órgano jurisdiccional determinado por la Ley.

34 Véase: ESCUELA DEL MINISTERIO PÚBLICO y OFICINA DE LAS NACIONES UNIDAS CONTRA LA DROGA Y EL DELITO. Talleres de Capacitación: Nuevo Proceso Penal Acusatorio. Módulo 1: Teoría del delito y mecanismos de investigación criminal. Perú, 2008. P. 5. 


\begin{tabular}{|c|c|c|c|}
\hline DEFENSOR & $\begin{array}{l}\text { - Tiene derecho de participa- } \\
\text { ción y controversia. } \\
\text { - Su intervención es para } \\
\text { ejercer derecho a la contro- } \\
\text { versia de las actuaciones de } \\
\text { la fiscalía en la preparación } \\
\text { de la prueba, velar por los } \\
\text { derechos fundamentales de } \\
\text { su patrocinado y buscar la } \\
\text { mejor opción o estrategia } \\
\text { de defensa. }\end{array}$ & $\begin{array}{l}\text { Facultado para contradecir } \\
\text { la acusación, ofrecer medios } \\
\text { probatorios, interponer cues- } \\
\text { tiones previas, prejudiciales, } \\
\text { excepciones, impugnar los } \\
\text { medios de prueba ofrecidos } \\
\text { por la fiscalía. }\end{array}$ & $\begin{array}{l}\text { - Es parte procesal. } \\
\text { - Ejerce una defensa } \\
\text { estratégica a través de la } \\
\text { refutación o de la demos- } \\
\text { tración de debilidades en } \\
\text { la teoría del caso de la } \\
\text { fiscalía. }\end{array}$ \\
\hline JUEZ & $\begin{array}{l}\text { Juez de la investigación } \\
\text { preparatoria: } \\
\text { - Verifica y controla el respeto } \\
\text { de las garantías del imputado. } \\
\text { - Decide sobre las medidas } \\
\text { limitativas o restrictivas, o de } \\
\text { coerción procesal solicitadas } \\
\text { por el fiscal. } \\
\text { - Controla el plazo y las } \\
\text { prórrogas de la investigación. } \\
\text { Decide sobre la actuación } \\
\text { de la prueba anticipada e } \\
\text { interviene en su actuación. }\end{array}$ & $\begin{array}{l}\text { Juez de la investigación } \\
\text { preparatoria: } \\
\text { - En la audiencia preliminar de- } \\
\text { cide sobre la procedibilidad de } \\
\text { la solicitud de sobreseimiento } \\
\text { o de acusación del fiscal. } \\
\text { - Resuelve las cuestiones e } \\
\text { impugnaciones planteadas } \\
\text { por la defensa contra la } \\
\text { acusación fiscal. }\end{array}$ & $\begin{array}{l}\text { Juez penal (unipersonal } \\
\text { o colegiado): } \\
\text { - Dirige la audiencia de } \\
\text { juicio oral. } \\
\text { - Garante del debido } \\
\text { proceso. } \\
\text { - Escucha los argumentos } \\
\text { de las partes, presencia la } \\
\text { actuación de las pruebas } \\
\text { y las valora. } \\
\text { - Decide sobre la respon- } \\
\text { sabilidad o inocencia del } \\
\text { acusado y, de ser el caso, } \\
\text { impone la pena. } \\
\text { - La sentencia puede ser } \\
\text { impugnaday su revocato- } \\
\text { ria o confirmación estará } \\
\text { a cargo de la Sala Penal } \\
\text { de Apelaciones. }\end{array}$ \\
\hline
\end{tabular}

Esquema elaborado por el autor.

\subsection{La oralidad}

Desde una visión estricta, como la sustentada por ROXIN (2000, p. 115)

"[u]n proceso es oral si la fundamentación de la sentencia se realiza exclusivamente mediante el material de hecho, introducido verbalmente en el juicio. Lo rigurosamente oral es la ejecución de la prueba, los informes de las partes y la "última palabra" del imputado (la oralidad, si bien tiene la ventaja de la expresividad, frescura $y$ rapidez, tiene como consecuencia los peligros de la falta de atención y del olvido) mientras que puede ser escrita la instrucción, la fase intermedia, la prueba documental -que en juicio habrá de ser leída-, la sentencia y el procedimiento recursal».

Entonces, en un proceso regido por el principio de oralidad, no todos los actos procesales necesariamente se realizan de forma verbal. Por tanto, lo decisivo para la calificación de un proceso como oral es su fase probatoria, en tanto que, el proceso es escrito, si la sentencia se elabora conforme al resultado de las actas que integran el expediente.

No obstante, consideramos que el principio de oralidad se manifiesta en diversos momentos del 
procedimiento, como por ejemplo, cuando el fiscal oraliza su requerimiento de prisión preventiva, cuando el defensor alega el control del plazo, cuando las partes ofrecen sus medios probatorios en la audiencia de control de acusación, cuando las partes exponen sus alegatos de apertura en el juicio oral, cuando las partes actúan la prueba en juicio e, incluso, cuando el apelante sustenta su impugnación ante la Sala Superior. En ese sentido, en un contexto acusatorio, la oralidad es un principio que rige no sólo la audiencia de juicio oral, sino todo el procedimiento. Este principio permite que el juzgador tenga una mejor apreciación del debate y de la información que se desprenda de la audiencia, todo lo cual le permitirá llegar a un convencimiento mucho más vinculado a la realidad, a la «verdad» $y$ consecuentemente, emitir un fallo adecuado, fundamentado y justo; por lo que hoy, en referencia al principio de oralidad, el juzgador decide con base a lo debatido y demostrado en la audiencia respectiva. (Salas, 2010).

El sistema acusatorio impone un régimen de audiencias, con lo cual se busca dejar atrás el ritualismo escrito, a efectos de hacer más dinámico su desarrollo. Las argumentaciones de las partes serán orales ante el juez competente y han de ser convincentes, por lo que dicha labor no puede ser dejada al azar o a la improvisación. El nuevo modelo procesal acarrea la necesidad que los operadores jurídicos adquieran conocimientos y destrezas en técnicas de litigación oral, a fin de desenvolverse adecuadamente en audiencia y sustenten sus respectivas posiciones. Cuando hablamos de técnicas de litigación oral, nos referimos al conjunto de habilidades y métodos a emplearse por las partes para la elaboración del planteamiento de su posición (de acusación o de defensa) en el proceso penal, para su sustentación en el debate contradictorio y para su demostración a través de la actuación estratégica de los medios probatorios, todo lo cual importa la proyección y justificación de la teoría del caso, la exposición impactante de los alegatos, la eficaz formulación de preguntas y objeciones en el interrogatorio y contrainterrogatorio y la adecuada oralización de los medios probatorios. Lo que en conjunto busca generar convicción en el juez, respecto a la certeza de sus argumentaciones.

El adecuado manejo de las técnicas de litigación oral, determinan el desempeño exitoso de las partes en el proceso penal y la única forma de dominar dichas técnicas y destrezas es a través de la experiencia. Poner en práctica las pautas proporcionadas, nos permitirá apreciar los errores y falencias relacionadas al conocimiento del caso, al empleo del lenguaje, a la forma en que se transmite el mensaje, a las preguntas y objeciones que formulamos, etc.

\section{CONCLUSIONES Y RECOMENDACIONES}

- Rasgos esenciales del proceso penal acusatorio. Queda claro que el sistema acusatorio se caracteriza por establecer una separación y delimitación de funciones de los sujetos procesales, en las diversas etapas del proceso penal. Es decir, que la funciones de persecución y las de decisión, se encuentran separadas y a cargo de dos órganos distintos: Ministerio Público y Poder Judicial, respectivamente. Asimismo, el nuevo proceso penal se destaca por ser esencialmente oral, adversarial y garantista. El principio de oralidad determina la existencia de un régimen de audiencias, es decir, que las decisiones del juzgador se basarán en lo debatido y demostrado en la audiencia respectiva. Lo adversarial deriva del principio de contradicción y radica en la posibilidad que tienen las partes, para poder ejercer sus refutaciones contra el argumento adverso. $\mathrm{El}$ garantismo implica el reconocimiento expreso de derechos y garantías a favor del imputado, mientras se encuentre sometido al proceso, pero también se consagran derechos a favor de la víctima del delito. En suma, el sistema de administración de justicia, exige que el garantismo vaya acompañado de eficiencia en la aplicación del Derecho Penal.

- La reforma procesal penal en el Perú. A través del CPP-2004, el Perú adoptó el sistema 
acusatorio en atención a presiones internas y externas. A nivel nacional era evidente la alarmante situación en la que se encontraba la administración de justicia penal: sobrecarga procesal, lentitud de los procesos, trámites atentatorios de los derechos fundamentales de los procesados, olvido e indefensión de las víctimas, altos índices de corrupción, impunidad, desconfianza de la sociedad en el sistema de justicia, etc., en tanto que a nivel internacional, la mayoría de países de la región han adoptado un sistema procesal acusatorio, para enfrentar los conflictos derivados del delito y buscar un mecanismo más civilizado para aplicar el Derecho Penal. En el Perú el proceso de implementación gradual del CPP-2004 comenzó en el año 2006 y se tiene programado que se culmine en el año 2013, si se logra superar el escoyo del presupuesto público y se cuenta con una seria decisión política.

- El nuevo proceso penal peruano. Se ha incorporado un nuevo trámite, denominado «proceso común», porque se aplica a todos los delitos prescritos en el Código Penal. Este proceso común cuenta con tres etapas: la investigación preparatoria, la etapa intermedia y el juzgamiento. Pero, el CPP-2004 también establece procesos especiales, como son: el proceso inmediato, el proceso por delitos de función, el proceso de seguridad, el proceso por delito de ejercicio privado de la acción penal, el proceso de terminación anticipada, el proceso por colaboración eficaz y el proceso por faltas.

\section{- Implicaciones del sistema acusatorio en}

el Perú. El proceso de reforma que afronta el Perú implica un cambio del sistema mixto a uno acusatorio, caracterizado por diseñar un proceso penal basado en el respeto de los derechos humanos contenidos en instrumentos internacionales y en la Constitución Política. Quizás lo más importante para un ciudadano que se ve involucrado en un proceso penal, sea saber que bajo un sistema acusatorio el poder sancionador del Estado encuentra límites o barreras que impiden un ejercicio abusivo, arbitrario o ilegal del poder en relación a la persona sometida a la jurisdicción. A cinco años de la puesta en vigencia del CPP-2004, apreciamos sus primeros resultados, tanto positivos como negativos. Sin duda que los primeros superan a los segundos. Entre las ventajas que trae consigo este nuevo código adjetivo, tenemos el rasgo garantista del proceso penal, el cual obliga al juzgador (y a los demás sujetos procesales), a respetar los derechos fundamentales del investigado o procesado, durante la tramitación del proceso, dotando a la defensa del imputado de las garantías eficaces, que le permitan reclamar cualquier afectación injustificada y/o desproporcionada; pero también, se prevé protección a la víctima del delito y a los testigos, a través de un cúmulo de medidas de protección, que garantizan su seguridad, de igual modo, se busca reparar el daño causado a la víctima de manera integral; de otro lado, la estructura del nuevo procedimiento y los mecanismos de simplificación procesal, permiten que los casos sean resueltos de manera anticipada, es decir sin necesidad de llegar a juicio oral $e$ inclusive, puede solucionarse el conflicto a nivel fiscal, a consecuencia de ello, los justiciables obtienen justicia oportuna, se descongestionan los despachos judiciales y el Estado ahorra los costos que devienen de latos procesos; entre otras.

Entre los aspectos más problemáticos resaltan el escaso presupuesto con el que cuentan las instituciones involucradas con el sistema de administración de justicia penal, como son la Policía Nacional, el Ministerio Público, el Poder Judicial y el Ministerio de Justicia; la falta de difusión de las bondades de la nueva legislación procesal a la colectividad, lo que se evidencia con la aún imperante cultura inquisitiva y de litigio, que pone trabas a la cultura del acuerdo y de la paz social; entre otros. A nivel jurídico y académico, también hemos apreciado ciertos vacíos y deficiencias, básicamente, referidos a la interpretación de algunas disposiciones del CPP-2004, las 
que han tenido que ser resueltas a través de casaciones penales emitidas por la Corte Suprema de la República; y referidos al desenvolvimiento de los operadores de justicia, durante este nuevo proceso penal en el que impera el régimen de audiencia.

- Recomendaciones. La adopción y la puesta en vigencia de toda norma jurídica nueva, que implica una reforma sustancial -como lo es el CPP-2004-, acarrea naturalmente la aparición de apreciaciones distintas, discusiones y errores en su aplicación. Revisada la evolución legislativa y analizado el contexto, aparecen pautas destinadas a encaminar la reforma, entre las cuales destacan, la seria decisión política del gobierno, por mejorar el sistema de administración de justicia penal, la habilitación de un presupuesto adecuado para la dimensión de las mejoras que se pretenden, la atención y el trato digno a los operadores involucrados con el sistema (policías, fiscales, jueces, auxiliares jurisdiccionales, etc.), la capacitación académica de nivel, la elaboración de políticas de coordinación interinstitucional, difusión de la reforma hacia la sociedad, entre otras. No obstante, debemos de precisar que este código no es la solución a la criminalidad, ni el remedio para el deficiente sistema de administración de justicia, estos aspectos requieren de atención a factores estructurales de índole social, político, económico, cultural, etc.

Par concluir se expresan las felicitaciones para quienes viven este momento histórico y tienen en sus manos la alta y noble labor de lograr el cambio -para mejor- del sistema de justicia penal: ustedes.

\section{BIBLIOGRAFÍA}

BLANCO SUÁREZ, Rafael, Mauricio DECAP FERNÁNDEZ, Leonardo MORENO HOLMAN y Hugo ROJAS CORRAL. (2005). Litigación Estratégica en el Nuevo Proceso Penal. $1^{\circ}$ edición. Santiago de Chile. $\mathrm{C}$ y $\mathrm{C}$ impresores.
COMISIÓN DE SEGUIMIENTO DE IMPLEMENTACIÓN DEL NUEVO CÓDIGO PROCESAL PENAL DE LA CORTE SUPERIOR DE JUSTICIA DE LA LIBERTAD. (2010). Informe estadístico La reforma Procesal Penal en Cifras. Una nueva visión de justicia. Año I - Nº1. Trujillo. Corte Superior de Justicia de La Libertad.

COMISIÓN INTERINSTITUCIONAL PARA EL IMPULSO DE LA ORALIDAD EN EL PROCESO PENAL, AGENCIA DE LOS ESTADOS UNIDOS PARA EL DESARROLLO INTERNACIONAL y PROGRAMA DE FORTALECIMIENTO Y ACCESO A LA JUSTICIA. (2003). Técnicas del Juicio Oral en el Sistema Penal Acusatorio Colombiano. Lecturas Complementarias. Bogotá. USAID.

COMISIÓN INTERINSTITUCIONAL PARA EL IMPULSO DE LA ORALIDAD EN EL PROCESO PENAL, AGENCIA DE LOS ESTADOS UNIDOS PARA EL DESARROLLO INTERNACIONAL y PROGRAMA DE FORTALECIMIENTO Y ACCESO A LA JUSTICIA. (2003). Técnicas del Juicio Oral en el Sistema Penal Acusatorio Colombiano. Libro del Discente. Bogotá. USAID.

DUCE J., Mauricio, FUENTES M., Claudio y RIEGO R., Cristián. (2009). La reforma procesal penal en América Latina y su impacto en el uso de la prisión preventiva. Santiago de Chile. Centro de Estudios de Justicia de las Américas - CEJAMERICAS.

ESCUELA DEL MINISTERIO PÚBLICO $y$ OFICINA DELASNACIONES UNIDAS CONTRA LA DROGA Y EL DELITO. (2008). Talleres de Capacitación "Nuevo Proceso Penal Acusatorio. Módulo 1: Teoría del delito y mecanismos de investigación criminal". Lima. Escuela del Ministerio Público y Oficina de las Naciones Unidas contra la Droga y el Delito.

ESCUELA DEL MINISTERIO PÚBLICO y OFICINADELASNACIONESUNIDAS CONTRA LA DROGA Y EL DELITO. (2008). Talleres de Capacitación "Nuevo Proceso Penal Acusatorio. Módulo 2: Técnicas de Sustentación y Litigación 
Oral”. Lima. Escuela del Ministerio Público y Oficina de las Naciones Unidas contra la Droga y el Delito.

LORCA NAVARRETE, Antonio María. (2009). Estudios sobre Garantismo Procesal. $1^{\circ}$ Edición. País Vasco. Instituto Vasco de Derecho Procesal.

MIXÁN MÁSS, Florencio. (1990). Derecho Procesal Penal. Tomo 1. Segunda edición. Trujillo, Perú. Editorial Marsol.

NEYRA FLORES, José. (2007). Manual de Juzgamiento, Prueba y Litigación Oral. En: ACADEMIA DE LA MAGISTRATURA. Código Procesal Penal - Manuales Operativos - Normas para la implementación. Lima. AMAG.

PEÑA CABRERA FREYRE, Alonso Raúl. (2007). Exégesis del Nuevo Código Procesal Penal. $1^{\circ}$ edición. Lima. Editorial Rodhas SAC.

PÉREZ SARMIENTO, Eric Lorenzo. (2009). Manual de Derecho Procesal Penal. $3^{\circ}$ edición. Venezuela. Vadell Hermanos Editores C.A.

ROXIN, Claus. (2000). Derecho Procesal Penal. Buenos Aires. Editores del Puerto.

SALAS BETETA, Christian. (2011). El proceso penal común. Lima. Gaceta Penal \& Procesal Penal.

SALASBETETA, Christian. (2010). Trascendencia de las técnicas de litigación oral en el proceso penal. Lima. Librería y Ediciones Jurídicas.
SAN MARTIN CASTRO, César. (2003). Derecho Procesal Penal. Tomo I y II. $2^{\circ}$ edición. Lima. Editorial Grijley.

SAN MARTIN CASTRO, César. (2005). Derecho Procesal Penal. Tomo I. Lima. Editorial Grijley.

SÁNCHEZ VELARDE, Pablo. (2004). Manual de Derecho Procesal Penal. Lima. Editorial Idemsa.

SÁNCHEZ VELARDE, Pablo. (2005). Introducción al Nuevo Proceso Penal. Lima. Editorial Moreno S.A.

\section{Leyes emitidas por el congreso de la república del perú}

1939 Ley N 9024 - Código de Procedimientos Penales. 23 noviembre.

1968 Decreto Ley № 17110. 03 octubre.

1981 Decreto Legislativo Nº 052 -Ley Orgánica del Ministerio Público. 18 marzo.

1981 Decreto Legislativo $N^{\circ} 124$ - Ley del proceso penal sumario. 12 junio.

1991 Decreto Legislativo Nº38 - Código Procesal Penal. 27 abril.

1993 Constitución Política del Perú. 30 diciembre.

2004 Decreto Legislativo N 957 - Código Procesal Penal. 29 julio. 